\title{
Impact of Anthropogenic Factor on Urboecological Space Development
}

\author{
Tamara Kuprina ${ }^{1 \mathrm{a}}$, and Lyubov Sergeeva ${ }^{2}$ \\ ${ }^{1}$ Ural Federal University, International Economics Department, 620002, Yekaterinburg, Russia \\ ${ }^{2}$ Ural Federal University, Fundamental Education Department, 620002, Yekaterinburg, Russia
}

\begin{abstract}
The article discusses the issues of the impact of the anthropogenic factor on urboecological space development. The issues are considered taking into account retrospective theoretical data to show the process of Anthropoecology development as a new branch of sociological science. At present the noosphere acquires features of anthropoecosystems having a number of parameters from the endogenous and exogenous point of view. Anthropoecology has special socio-cultural significance as considers the interaction of all actors of international space. There introduced the new branch Ecopsycology as the outer world is the reflection of the inner human world. There is a definition of the sustainability of ecological system. In the practical part of the article there is an example of academic mobility as the basis of the human potential with possible transfer into the human capital supporting by survey data. In conclusion there are recommendations on management and adaptation of the anthropogenic factor (a kind of biogenesis) in modern urboecological space.
\end{abstract}

Today's global challenges raise a number of major transformations in all spheres of the society life. However, it should be noted that, in speaking of the system of comfortable conditions creation for living in urboecological space, experts generally have in mind the technical, political, economic, legal aspects, often underestimating the humanitarian component: the human factor. This factor is important, first of all, because all ecological problems are generated by the people themselves.

At present, there is a separate branch of knowledge: Human Ecology (Anthropoecology). And, if earlier it concerned mainly the physiological state, now there is an interdisciplinary approach that includes social ecology, urban ecology, culture ecology and others.

The proposed concept includes not only the traditional consideration of ecology of human relations and society with nature, but also the relationships between the structural units of the society. In Anthropoecology the object of research is social processes in relation to the state of the subject (person, group of people, including intercultural community), which appear in different areas of life.

The area is closely related to Urboecology, studying not only the features of the ecological space of the city and urbanization, but also the influence of anthropogenic

\footnotetext{
${ }^{a}$ Corresponding author: tvkuprina@mail.ru
} 
factors on the development of the urban space. Thus, it is necessary to study the human factor, constantly moving from one ecological niche to another (housing, work and study places, transportation, recreation, etc.). Moreover, with increasing urbanization and space alienation processes people must have the complex adaptive mechanisms (physiological, psychological, social) that are not limitless, but they can be developed and improved. In particular, it is necessary to take into account the cultural and historical space of the city, including the social and spiritual environment, considering historical processes, cultural traditions prevailing in the country and region specified.

In today's Urboecology one must take into account the demographic and migratory factors. Transnational migration flows involve not only the labor and professional migration, but academic migration as well, the number of which increases with each passing year. The high degree of academic mobility requires a well-developed infrastructure (hostels, health insurance, etc.), availability of financing sources (scholarships, travel grants, etc.), high language skills of students and lecturers enable to teach and study abroad as well as the psychological readiness of academic migrants to adapt to the new conditions.

Consequently, practical activities should be aimed at optimizing the interactions between all the actors involved: analysis of interacting social structures in different sociocultural contexts, their adequate assessment and interaction with different gender, ethnic, age and other groups under the urbanized space. It is necessary to take into account the experience and development features of other cultural communities.

Some authors distinguish Anthropoecology as a separate field and as an integrated discipline that combines elements of ecology and anthropology, and studies the human activity, interacting with nature, society and culture. There are factors determining the quality of life, individual values and the problem of their improvement. Moreover, this approach to the solution of educational problems raises from the fact that human is the highest value and measure of effectiveness of civilization as a way to organize the human lives and communities (a prosperous society) [1]

On the other hand, Anthropoecology researches the relationship laws of the biosphere and human anthrosystem, their groups and individuals, the impact of natural and social space on the individual and their groups, human populations, including ethnic groups [2].

Thus, Anthropoecology is an integrated discipline, where all social, economic, natural and cultural factors are considered as equivalent components of human lives, providing different levels of their needs.

Theoretical concepts are based on different approaches to the interpretation of social interactions in ecological space. However, yet Aristotle, F. Akvinsky, N. Machiavelli clearly traced parallels between natural and social development of the society.

Auguste Comte drew attention to the labor division and solidarity. E. Durkheim pointed to the cultural artifacts and linked them with the collective representations. M. Weber considered mutually oriented or social actions of people as a unified factor.

In XIX century, due to H. Spencer, there appeared a new social and biological direction, interpreting living beings from a social point of view. At the same time there formed Ecology as a discipline (E. Haeckel, 1866), connecting biological and sociological concepts.

R. Park and E. Burgess (Chicago Social School, 1921) founded the direction "Human Ecology", which later received other names: Anthropoecology and Environmentology. Its purpose is to define the processes of interaction between the environment and human communities as well as their impact on human activity.

A. Tensli (1935) introduced the term "ecosystem" (Greek oikos - home, settlement, and systema - combination, association), which is understood as a set of co-inhabiting organisms and the conditions of their existence, being in a logical relationship with each 
other and forming a system of interdependent biotic and abiotic processes and phenomena [3].

A. Tensli emphasized that ecosystems were the main natural units comprising both a complex of organisms and physical factors that made up biomes' space, i.e. habitat factors.

In the Russian science V. Sukachev (1940) coined the term "biogenesis" as a homogeneous area of the earth surface with a defined composition of living (biogenesis) and inert (surface layer of the atmosphere, solar energy, soil, etc.) components, integrated by metabolism and energy exchange in a single natural complex. Moreover, ecosystems can have arbitrary boundaries (from a drop of water to the biosphere as a whole), while the biogenesis always occupies a certain territory [3].

As noted by E. Kogay, ecosystems strive for balance between the number of organisms and habitat capacity (the ability of habitat to allow the ecosystem to exist without affecting its constituent components). This balance is not static; it is flexible, changeable within certain limits defined by the terms of the maintenance of the basic parameters of the ecosystem functioning. Going beyond these limits (often by human intervention) can lead to destructive processes in the system or changing its fundamental components [4].

V.I. Vernadsky and then his follower A.E. Fersman point out that with the development of industrial activity a human becomes a major geological factor of all changes on the planet. Thus, the biosphere transforms into a qualitatively new state, indicated by V.I. Vernadsky as the "noosphere". Moreover, technical and social backgrounds of the noosphere appear long before the human awareness of the need to shift to the noosphere.

In this case, technical and social prerequisites for the noosphere are: a sufficiently high level of technological development, energy security and scientific knowledge; overcoming the economic, political and racial separateness of people with absolute exclusion of any military conflicts from the interrelations between the peoples. ... An important social condition of the noosphere is a need of transition of all humanity to a higher degree of social integration. Humanity can only survive as a single entity [5].

One of the transitions of the biosphere into the noosphere is the process of urbanization. The city comprehensively creates many aspects of human life. In assessing the degree of the ecological comfort of the city one must take into account, in particular, the components of the citizens' life, as the level of social welfare (family budgets, housing, services, education, health, quality of medical care and social security, etc. ), the degree of ecological safety and legal protection, employment and satisfaction with work (scope of employment, relationships at work, transport and pedestrian accessibility of the work place, etc.), the conditions for a good rest and recuperation, the completeness degree of information support and the existence of conditions for the continuity of cultural traditions etc. Thus, the macroenvironment of the city consists of numerous microenvironments that impact the well-being of people [6].

In modern conditions there is a new kind of noosphere: anthropoecosystem. From B.B. Prokhorov's point of view, anthropoecosystem is a spatial subdivision of the human environment, in all its parts having the similarity of natural, social, economic, industrial, ecological and hygienic, cultural and domestic, informational conditions of human life, which form the worldview and environmental awareness, health level, demographic behavior, physical appearance, labor skills, lifestyle, customs and traditions, choice of religion, professional preferences, etc. Anthropoecosystem is an ecosystem in which human activity takes place [7].

Anthropoecosystem has a number of characteristics:

1. Internal homogeneity and external heterogeneity with other similar systems;

2. Takes a certain space; 
3. Self-development is gradual over long periods of time;

4. Rapid change gives rise to new systems and often undesirable phenomena for the human society.

Anthropoecosystem includes a variety of elements such as nature, economy, population, socio-economic conditions. Moreover, all the elements are interconnected and changes in both individual elements and their combinations impact on the human behavior, whose community is a central element of the system. Thus, there are changes in environmental awareness, demographic and professional behavior, health, culture and education levels.

In this context, one can talk about socialization, i.e. specific adaptation of a human or group of people to the social environment. Consequently, there is a need to ensure the conditions meeting the needs and interests of the people and contributing to the achievement of important vital goals.

L.K. Kruglova allocates a separate direction, i.e. socio-cultural Anthropoecolology, whose subject is laws of the structure, functioning and development of the ecosystem, elements of which are human, nature, society and culture [8].

Of particular relevance to human is such an element of cultural microenvironment, as home of a wide socio-cultural sense. Home means a family, its spiritual atmosphere, life style, objects in the house, and, finally, the very image of home, that is a kind of unity. It is at home where a human has an opportunity to put into practice all the principles of interaction with the socio-cultural environment, all the ways of overcoming its negative states [8].

The newest trend is Ecopsychology, which tries to combine the transformation of the individual and society. Ecopsychologist Jean-Pierre Le Dunff notes that according to the tenets of the science, the outside world is a reflection of the inner world of humans [9].

In general, the subject of research of ecopsychology is ecological consciousness as a set of ideas about the relation to nature, strategies and technologies of interaction with it on socio-genetic, ontogenetic and functional levels.

In this regard, one can speak of a certain ecosystem sustainability contributing to the sustainable development of the society. For example, E. Tsukanov offers the following definition of ecosystem sustainability: the sustainability of the ecosystem is an ability to withstand environmental fluctuations, while retaining its structural and functional integrity [10].

However, sustainability can constantly be disturbed by external factors. One of the most difficult aspects of modernity is the problem of international migration, as demonstrated by the migration crisis in Europe which has received millions of socially non-adapted representatives of many cultures, dramatically different from the European one. The protective reaction of migrants can be considered as the formation of ethnic enclaves in the host areas, preserving the behavior standards and traditions of national cultures.

At the same time, there are other "soft" kinds of migratory flows, in particular, the academic migration. The advanced format of the flow includes not only students but also post-graduate and doctoral students, students of preparatory and language courses, seminars, internships, i.e. it is a migratory flow caused by getting an education in the broadest sense [11]. In the Russian migration flow academic migration takes the third place after the labor migration and resettlement of compatriots.

Researchers of academic migration show that every year there is an increasing competition between countries for academic migrants as foreign students are both a norm of international cooperation and "soft power" in the context of the geo-cultural space, and future "quality labor migrants" (young, embedded in the socio-cultural context). The increase share of academic migration in the total migration flow provides greater manageability of the immigration process; consequently, the academic migration can be considered an important component in the security concept of any country [12]. 
However, there are several problems associated with adaptation of academic migrants in the new intercultural space.

First of all, experts argue that our time is the era of customized environment. The younger generation "customizes" the world, making it more convenient fro them. Students should be able to "adjust" to some extent, the learning process, so that each of them has the most convenient way to gain knowledge [13]. It is necessary to add that they customize not only training, but also urbanized space.

Therefore, the Russian education system faces an issue of life and study optimization of foreign students, who are going through a difficult process of adaptation to new conditions of life.

There is no doubt that in order to attract foreigners to study the quality of the living conditions for students is of great importance, as each country has its own peculiarities of everyday life and foreign students have to accept different norms and rules of behavior, communication, keeping household. The important problem for foreign students is the language barrier. In order to improve the learning process of foreign students it is necessary to develop their professional and linguistic competence [14].

To determine the specific problems of academic migration adaptation in the urboecological environment, we conducted a pilot survey among foreign students at first-year full-time training. The sample consists of 40 people, arrived at the Ural Federal University (UrFU) in 2015. We use the copyrighted methodology by I.A. Sholokhov, aimed at identifying the difficulties in communicating in a foreign language, the presence of the motivation to study and determine the total adaptation of students for life in the new environment and identify the students' loyalty to another cultural society. The survey involved students from 20 countries, 16 far abroad countries (Kenya, Zambia, Mongolia, Mexico, China, Pakistan, Egypt) 4 the CIS countries (Kyrgyzstan, Tajikistan, Kazakhstan, Uzbekistan).

The results show that 37 out of 40 have problems in intercultural communication, associated with lack of knowledge of a foreign language or a reluctance to join the cultural environment, to learn and adapt to new conditions. Students are not used to the new conditions of life, and the adaptation is difficult. Only 3 students out of the total sample identify themselves with the student environment and strive to fully adapt to it, to learn, to immerse in the new language environment, they have a positive motivation for learning activities.

Answers of half of the respondents indicate inadequate assessment of their position in the cultural environment and the poor adaptation to changes in living conditions. 10 respondents have no active socio-cultural position. 8 out of $40(20 \%)$ are loyal to the cultural environment in which they are located, respectively, they can successfully adapt to the new conditions of life. 2 respondents have not formed a clear position yet, and there is no particular motivation to educational activity, it is likely that students can stop learning.

There are some issues related to the urboecological adaptation.

1. "Settlements of foreign students should be focused, but not dispersed across the city". Students' opinions are as follows: "Yes" - 25 respondents, 10 - "No" and 5 - difficult choice. It also shows that the majority of the respondents prefer to live in the same place with people of their own ethnicity, close to the university, as their navigation in the city is difficult, it also means a low adaptability level to the life conditions in another country.

2. "Development of services for international students is their own concern, rather than the local authorities." The students respond as follows: 10 people agree with the statement, 21 people do not agree with the expression and 9 people found it difficult to answer. More than half of respondents believe that the regional authorities should take care of the development of services for international students. This issue is a control point for 
a series of issues about the student's loyalty to the community and other cultures and the answer "do not agree" indicates the inadequate assessment of their position in the cultural environment and bad adaption to changes in living conditions.

3."Would you like to have more national dishes for the foreign students in students' canteens?" 34 respondents answer "Yes", 3 - "No" and 3 - difficult choice, it shows that students miss home, their national cuisine, and that they are not adapted to local nutritional habits.

4."Educational institutions should provide special services for international students." The majority of respondents (35) answer "agree", 2 - "disagree" and 3 - difficult choice.

5. "With respect to foreign students social norms need to be more flexible" 33 respondents reacted to the positive response, only 3 people did not agree with the opinion and 4 difficult to answer.

Two last issues determine the overall adaptation of students for life in a new environment and positive answers "agree" of respondents suggest that adaptation is difficult and students are not used to the new space conditions.

Thus, the answers to the issues of urboecological character show both the weak adaptation of foreign students, and underdeveloped urbanized structure of the city, which should support the invited students, who could later become professionals in the area.

The presented pilot research compares favorably with most other ones as they are mainly based on ordinary questionnaire surveys, limited in number and aspects discussed. As far as the research presented in this article, it is based on a complex professional psychological tests that validity has been proved. Despite the limited sample (40 respondents) which is due to the beginning of the research, it can be a good example proving some data received by other experts.

So, according to their survey, foreign students admitted the following problems: climatic $(26 \%)$, hostel conditions $(21 \%)$, communication in the Russian language $(18 \%)$, new life style (14\%), natives' attitude (11\%), relatives' absence $(5 \%)$ and Russian cuisine $(3 \%)$ [15].

From our point of view, the extended research planning by the authors of the article can help better understanding of the problem and formulating new aspects of its solution.

In foreign universities for successful adaptation of students there are various mechanisms of socialization and adaptation. Typically, the host country students are engaged in the process by organizing the so-called clubs. If we consider the European experience, it is necessary to mention Buddy Building Club (BBC), the international volunteer club, which deals with the adaptation of foreign students on a voluntary basis [16].

Recently the similar project has been introduced in the Ural Federal University. "Buddy UrFU" is the foreign student support program aimed at creating a favorable environment for learning and socialization through the involvement of volunteers among students to meet and support foreigners on their first most difficult days of stay in the new country and help in solving a variety of domestic issues. Between August and December 2015 "Buddy UrFU" helped 700 foreign students.

The Ural Federal University has also set up its own associations to support foreign students, for example, Student United Nations Organization, the students' organization, formed in February 2012, in order to provide comprehensive assistance to foreign students to adapt to student's life at the university. Its main task is in continuous contact with the foreign students during the whole period of training (through students' fraternities that are created on the principle of territorial or national identity). The fraternities help students to adapt, monitor educational progress and help in solving problems. At the moment, there are 12 students' fraternities groups, uniting more than $70 \%$ of foreign students. 
Taking into account the theoretical principles mentioned above, and the practical results of our pilot survey, we can give the following recommendations:

1. Considering complex migration and demographic situation, academic migration should be seen as a possible source of human potential, followed by the formation of highquality human capital in the host urboecological space.

2. Assessing urboecological comfort of the city for receiving academic migration it should be taken into account the comfort of living conditions and their destination to socially significant objects.

3. Special attention should be paid to health and timely quality health care, as it is due to the difficulties of foreign students' adaptation to the climatic conditions. On the other hand, there is a need for prevention of Russian students' morbidity because foreign students can be carriers of unusual diseases for this urboecological space.

4. From the intercultural point of view, there must be conditions established for adaptation to new cultural traditions and norms of behavior, as well as the prevention of ethnic conflicts, taking into account the compact settlement of the fraternities' type.

5. The above-mentioned students' organizations will certainly help their fellows to adapt to the host urboecological space. However, from our point of view, it is not enough. Support of academic migration, i.e. the quality human potential, and subsequently the human capital what is socially and economically important in terms of demographic problems, should be dealt by official city agencies.

Thus, we can conclude that there are changes not only in natural and technological landscape in the urboecological space, but also in the demographic situation due to international migration. In this case, one can consider a certain biogenesis, anthropogenic factor, creating its own special urboecological space. Consequently, the human factor is becoming increasingly important defining features of the designing and maintaining urboecological systems.

\section{References}

1. S.V. Krivikh, A.A. Makarenya, Pedagogical Anthropology (SPB, 2003)

2. N.A. Agadzhanyan, Human Ecology (1997)

3. M.S. Gilyarov, Biological encyclopedic dictionary (M, 1986)

4. E.A. Kogay, Doctrine of biosphere and biosphere science class, SHK, 3, 92-105 (1999)

5. E.V. Girusov, Ecology and Economics of wildlife management. Available: http://nashaucheba.ru/v41859//

6. Urboecology and Anthropoecology. Available: http://ecology/00170400_0.html

7. B.B. Prokhorov, Human Ecology (2010)

8. L.K. Kruglova, Socio-cultural Anthropoecology as methodological basis for personality typology. Available: http://www.pandia.ru/text/78/461/6808.php

9. A. Grigoryeva, How to overcome ecological fatigue, Ps, 3, 122-124 (2016)

10. E. Tsukanov, Information society and Homo Informaticus. Available: http://www.bibliofond.ru/view.aspx?id=116652

11. O.D. Vikhovanets, Academic migration as a part of migration policy in Russia. Available: http://www.fms.gov.ru/about/science/science_session/forth/vih.pdf

12. E.S. Krasinets, International migration of Russian population in conditions of market transfer (2012)

13. D. Koats, Generational learning styles (2011)

14. L.V. Sergeeva, Demographic processes impact on the development of academic migration in Russia (Yekaterinburg, 2015)

15. A.D. Gladush, G.N. Trofimova, V.M. Filippov, Socio-cultural adaptation of foreign citizens to the conditions of studying and living in Russia (2008) 
16. E.N. Shpet, Mechanisms of social adaptation of students-migrants learning under academic mobility programs, SI TPU, 11, 170-172 